\title{
Structures, Energies, and Bonding Analysis of Monoaurated Complexes with N-Heterocyclic Carbene and Analogues
}

\author{
T.A.N. NGUYEN ${ }^{1}$, T.P.L. HUYNH ${ }^{1}$, T.X.P. VO ${ }^{1}$, T.H. TRAN ${ }^{1}$, D.S. TRAN ${ }^{2}$, \\ T.H. DANG ${ }^{3}$ AND T.Q. DUONG ${ }^{4}$
}

\begin{abstract}
In this work, we computationally investigated from quantum chemical calculations (DFT) at the BP86 level with the various basis sets def2-SVP, def2-TZVPP, and TZ2P+, chemical bonding issues

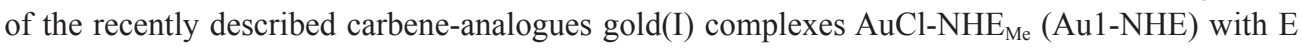
$=\mathrm{C}-\mathrm{Pb}$. The optimized structures and the metal-ligand bond dissociation energy (BDE) were calculated, and the nature of the $\mathrm{E} \rightarrow \mathrm{Au}$ bond was studied with charge and energy decomposition methods. The equilibrium structures of the system showed that there were major differences in the bonded orientation from the ligands NHC-NHPb to gold(I) complex between the lighter and the heavier homologues. The BDEs results showed that the metal-carbene analogues bonds were very strong bonds and the strongest bond was calculated for Aul-NHC which had the bond strength $D_{e}=79.2 \mathrm{kcal} / \mathrm{mol}$. Bonding analysis of Au1-NHE showed that NHE ligands exhibited donoracceptor bonds with the $\sigma$ lone pair electrons of NHE donated into the vacant orbital of the acceptor fragment $(\mathrm{AuCl})$. The EDA-NOCV results indicated that the ligand NHE in Au1-NHE complexes were strong $\sigma$-donors and very weak $\pi$ donor and the bond order in complexes was Aul-NHC > $\mathrm{Au} 1-\mathrm{NHSi}>\mathrm{Au} 1-\mathrm{NHGe}>\mathrm{Au} 1-\mathrm{NHSn}>\mathrm{Au1}-\mathrm{NHPb}$. We also realised that the gold-ligand bond was characterized by a $\pi$ back-donation component from the Au to the ligand. All investigated complexes in this study were suitable targets for synthesis and gave a challenge in designing $\mathrm{Au}$ nano-crystals of narrow size distribution from gold(I) complexes that carried versatile N-heterocyclic carbene-analogues NHE.
\end{abstract}

Key words: N-heterocyclic carbene ligands; bond dissociation energy; EDA-NOCV; gold; DFT calculations

The first direct synthesis of metal complexes with $\mathrm{N}$-heterocyclic carbenes (NHCs) as ligand was pendently presented by Hans Werner Wanzlick (Wanzlick 1968) and Karl Öfele (1968). After that the break through result of the isolation of stable carbenes was reported by Arduengo et al. (1991). It has been known that NHCs have emerged as an essential class of ligands in inorganic and organometallic chemistry (Bourissou et al. 2000; Hahn \& Jahnke 2008; Herrmann 2002). In the report of Jacobsen (Jacobsen et al. 2009) showed that NHCs display particular properties across the wide family of neutral ligands used in catalysis due to strong $\sigma$-donating character. Furthermore, ligand NHCs exhibit a special

\footnotetext{
Department of Chemistry, Hue University of Sciences, Hue University, 77 Nguyen Hue, Hue, Vietnam

${ }^{2}$ Department of Chemistry, Quang Binh University, 312 Ly Thuong Kiet, Dong Hoi, Quang Binh, Vietnam

${ }^{3}$ HCMC University of Food Industry, 140 Le Trong Tan, Tan Phu, Ho Chi Minh, Vietnam

${ }^{4}$ Department of Chemistry, Hue University of Education, Hue University, 34 Le Loi, Hue, Vietnam

* Corresponding author (e-mail: ainhungnguyen.chem@gmail.com)
} 
geometry associated with a flexible structure allowing fine-turning of their steric properties (Poater et al. 2009). In addition to this, NHCs can be very popular used for a large variety of reactions of high synthetic interest and these two-coordinate forms of carbon with two unpaired electrons have been considered as "new" ligands for bioactive coordination compounds (Hermann et al. 2002; Nemcsok et al. 2004). It has been noted that NHCs ligands can be stabilized by two nitrogens and form stable complexes with transition metals $(\mathrm{Ag}, \mathrm{Au})$ and with main-group elements (Nemcsok et al. 2004). Although the first stable transition metal carbene complex was investigated in 1964 (Fischer \& Maasböl 1964), but after a long time, the metal-ligand bonding in complexes of mixed carbene-halogen complexes (NHC-TMX with TM $=\mathrm{Cu}, \mathrm{Ag}, \mathrm{Au}$ and $\mathrm{X}=\mathrm{F}-\mathrm{I}$ ) was published for using a charge decomposition analysis which was noticed for the first time by Frenking and Boehme (1998) and group 11 elements $(\mathrm{Cu}, \mathrm{Ag}, \mathrm{Au})$ called as coinage metals, have aroused intense interest (Zhu et al. 2012). The chemical bonding between NHCs and group 11 metals have been investigated theoretically (Nemcsok et al. 2004; Hu et al. 2004). Moreover, theoretical studies of the electronic structure of transition metal complexes with NHCs ligand have been recently carried out by other group (Schwarz et al. 2000; Weskamp et al. 1999; Lee et al. 2004). The fact was that, the type of NHC ligands that have been developed by Arduengo et al. [1991] have found recent use in the synthesis of molecular gold(I) fluoride and chloride complexes. Particularly in recent years, it has been known that gold could from stable coordination complexes with NHC ligand (Marion \& Nolan 2008; Nolan 2011; Zhu et al. 2012). The nature of the Au-NHC binding has been presented from the structures and properties of the complexes (Nemcsok et al. 2004). In this study, we want to choose $\mathrm{NHC}_{\mathrm{Me}}$ and to extend to the heavier homologues in order to give insight into the structures and bonding situation using NBO and energy decomposition analysis (EDA) with the set of orbitals - the natural orbitals for chemical valence (NOCV) methods. The main purpose of this study was to investigate in details the bond strength of Au-E bond; the nature of the $\mathrm{Au}-\mathrm{E}$ bond in $\mathrm{AuCl}$-ligands; and the differences in the Au-ligand bonding from the carbene to plumbylene complexes. Scheme 1 shows the overview of the compounds investigated in the presented work and the schematic representation of a donor-acceptor bonding in Fischer-type carbene complex is shown in Scheme 2. The $\mathrm{C}$ atom in $\mathrm{NHC}_{\mathrm{Me}}$ ligand retains one lone pairs which is formally formed from a carbene ligand in a triplet state to a triplet $\mathrm{AuCl}$ fragment. To understand the gold-chloride and NHE ligands interactions in complexes, we have carried out density functional theory calculations. We investigated the bonding situation in complexes and the electronic structure of the molecules was analyzed with charge- and energy-decomposition methods.

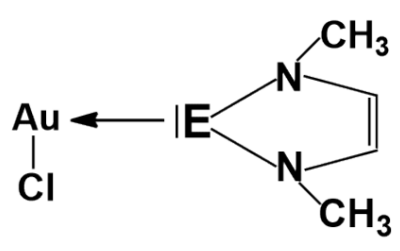

(a)

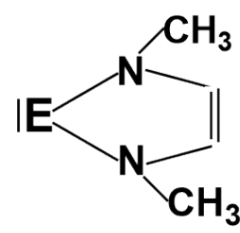

(b)
Scheme 1. Overview of the compounds investigated in the present work: (a) Complexes [AuCl-\{NHE $\left.\mathrm{Me}_{\mathrm{S}}\right\}$ (Au1-NHE) and (b) Ligand $N H E_{M e}(N H E)$ with $E=C, S i, G e, S n, P b$.

\section{COMPUTATIONAL DETAILS AND THEORETICAL ASPECTS}

The geometries of the gold(I) carbeneanalogues complexes [AuCl- $\left.\left\{\mathrm{NHC}_{\mathrm{Me}}\right\}\right]-$ $\left[\mathrm{AuCl}-\left\{\mathrm{NHPb}_{\mathrm{Me}}\right\}\right]$ (Au1-NHC - Au1-NHPb) were carried out at the gradient corrected DFT level of theory using Beck's exchange functional (Becke 1998) in conjunction with Perdew's correlation functional (BP86) (Perdew 1986). The calculations were carried out using 

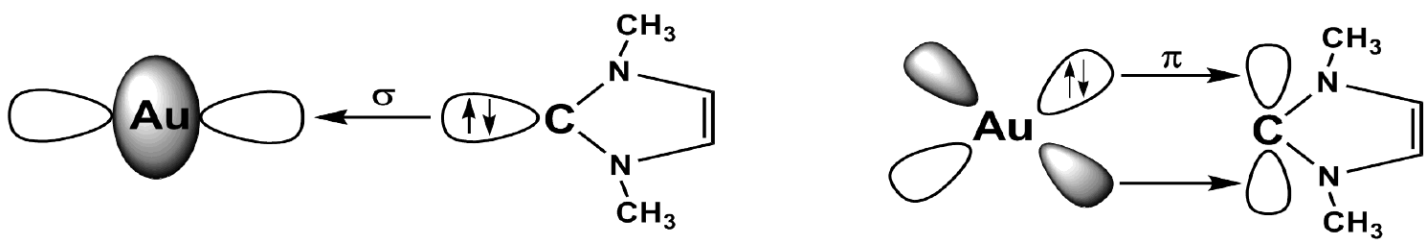

Scheme 2. Schematic representation of donor-acceptor bonding in Fischer-type of $\mathrm{AuCl}$ complex that carries NHC ligand.

the program package Gaussian03 (Frisch et al. 2004) optimized together with Turbomole 6.01 (Ahlrichs et al. 1989). All geometries were fully optimized without any symmetry constraints. A triple zeta valence basis set (def2-SVP) (Schäfer et al. 1992) was used for all of the main group elements and the relativistic of effective core potentials (ECPs) (Weigend \& Ahlrichs et al. 2005) were applied for the heavier group-14 atoms $\mathrm{Sn}, \mathrm{Pb}$, and atom $\mathrm{Au}$. The nature of the stationary points was checked by frequency calculations at the same level of theory (BP86/def2-SVP). All the structures of the complexes were verified as minimum by confirming that their respective Hessians were real on the BP86/def2-SVP level. The calculation of the bond dissociation energies (BDEs) and the charge analysis with Wiberg bond indices (WBI) as well as the natural partial charges at the BP86/def2-TZVPP (Snijders et al. 1981) //BP86/def2-SVP level of theory were carried out by using NBO 3.1 partitioning method in Gaussian03. Next, the bonding analysis was considered by using the ZieglerRauk-type energy decomposition analysis (EDA) (Ziegler \& Rauk 1977) and natural orbital for chemical valence (NOCV). All complexes on the BP86/def2-SVP optimized structures were re-optimized by using the BP86/ $\mathrm{TZ2P}+$ of core functional/basis set combination as implemented in ADF 2013.01 (Velde et al. 2001). An auxiliary set of $s, p, d, f$, and $g$ STOs was used to fit the molecular densities and to represent the Coulomb and exchange potentials accurately in each SCF cycle (Krijn \& Baerends 1984). Relativistic effects were taken by means of the zeroth-order regular approximation
(ZORA) Hamiltonian (Velde et al. 2001; Lenthe et al. 1993; Lenthe et al. 1996) with a small frozen core. The nature of the Au-E bonds in Au1-NHC-Au1-NHPb were investigated at BP86/TZ2P+ with the EDA-NOCV (Mitoraj \& Michalak 2007a; Mitoraj \& Michalak 2007b; Mitoraj et al. 2009) method which combines the EDA (Nemcsok et al. 2004) with the NOCV (Mitoraj \& Michalak 2007b; Mitoraj et al. 2009) under C1 symmetric geometries (without symmetry).

Herein, we want to present a detailed theoretical aspect about the EDA-NOCV method. The EDA gave very well-defined energy terms for the chemical bonds in molecules. In the EDA developed independently by different groups (Morokuma 1971; Ziegler \& Rauk 1979), and the recently introduced EDA-NOCV, the bond dissociation energy, $D_{e}$, of a molecule was divided into the instantaneous interaction energy $\Delta E_{i n t}$ and the preparation energy $\Delta E_{\text {prep }}$ :

$$
\Delta E\left(=-D_{e}\right)=\Delta E_{\text {int }}+\Delta E_{\text {prep }}
$$

The preparation energy $\Delta E_{\text {prep }}$ was the energy which was required to promote the fragments from their equilibrium geometries in the electronic ground state to the geometries and electronic reference state which they had in the molecule. The interaction energy $\Delta E_{\text {int }}$ could be further divided into three main components:

$$
\Delta E_{\text {int }}=\Delta E_{\text {elstat }}+\Delta E_{\text {Pauli }}+\Delta E_{\text {orb }}
$$

where, $\Delta E_{\text {elstat }}$ is the quasiclassical electrostatic interaction energy between the fragments, 
calculated by means of the frozen electron density distribution of the fragments in the geometry of the molecules. $\Delta E_{\text {Pauli }}$ was referred to the repulsive interactions between the fragments which were caused by the fact that two electrons with the same spin could not occupy the same region in space, and could be calculated by enforcing the Kohn-Sham determinant on the superimposed fragments to obey the Pauli principle by anti-symmetrisation and renormalisation. The stabilising orbital interaction term $\Delta E_{\text {orb }}$ was calculated in the final step of the energy partitioning analysis when the Kohn-Sham orbitals relaxed to their optimal form. The EDA-NOCV method combined the charge (NOCV) and energy (EDA) partitioning schemes to decompose the deformation density which was associated with the bond formation, $\Delta \rho$, into different components of the chemical bond. Furthermore, the EDA-NOCV calculations also provided pair wise energy contributions for each pair or interacting orbitals to the total bond energy. $\mathrm{NOCV}$ is defined as the eigenvector of the valence operator, v, given by Equation 4:

$$
v \psi_{i}=v \psi_{i}
$$

In the EDA-NOCV scheme the orbital interaction term, $\Delta E_{\text {orb }}$, is given by Equation 5:

$$
\Delta E_{\text {orb }}=\sum_{k=1}^{N / 2} \Delta E_{k}^{\mathrm{orb}}=\sum_{k=1}^{N / 2} v_{k}\left[-F_{-k,-k}^{\mathrm{TS}}+F_{k, k}^{\mathrm{TS}}\right]
$$

in which $F_{-k,-k}^{T S}$ and $F_{k, k}^{T S}$ were diagonal transition-state Kohn-Sham matrix elements corresponding to NOCVs with the eigenvalues $-v_{k}$ and $v_{k}$, respectively. The $\Delta E_{k}^{\text {orb }}$ term of a particular type of bond was assigned by visual inspection of the shape of the deformation density, $\Delta \rho_{k}$. The EDA-NOCV scheme thus provided information about the strength of orbital interactions in terms of both, charge $\left(\Delta \rho_{\text {orb }}\right)$ and energy contributions $\left(\Delta E_{o r b}\right)$ in chemical bonds.

\section{RESULTS AND DISCUSSION}

\section{Structures and Energies}

The theoretically predicted geometries of Au1-NHC-Au1-NHPb with bond length, bond angle, and bending angle are shown in Figure 1 together with Table 1. Complexes Au1-NHC$\mathrm{Au} 1-\mathrm{NHPb}$ clearly feature $\eta^{1}$ coordinated $\mathrm{AuCl}$ at the central $\mathrm{E}$ atom $(\mathrm{E}=\mathrm{C}-\mathrm{Pb})$. To the best of our knowledge, there was no experimental geometries for gold(I) complex that carried $\mathrm{NHE}_{\mathrm{Me}}$. Note that the theoretical study with geometries and bond dissociation energies of less bulky N-heterocyclic carbene, silylene, and germylene complexes of $\mathrm{MCl}(\mathrm{M}=\mathrm{Cu}$, $\mathrm{Ag}, \mathrm{Au}$ ) have been investigated by Boehme and Frenking (1998) for the first time in the recent past. Moreover, we have found somewhere else that the theoretical as well as the experimental geometries of related carbene complexes where the substituents at nitrogen was $\mathrm{R}=$ hydrogen, benzyl, benzoyl, were in good agreement with our calculated values (Boehme \& Frenking 1998; Bovio et al. 1993). The calculated Au-C bond length of Aul-NHC gives the shortest value (1.997 $\AA$ ) and the theoretically predicted Au-E bond lengths of complexes Au1-NHC$\mathrm{Au} 1-\mathrm{NHPb}$ in this study increased from 1.997 to $2.708 \AA$. This could be easily explained by the increasing radii of the group-14 atoms. The calculated equilibrium structures of complexes Au1-NHC-Au1-NHPb in Table 1 show that lighter ligands $\mathrm{NHE}(\mathrm{E}=\mathrm{C}-\mathrm{Ge})$ were bonded in a head-on way to the metal fragment $\mathrm{AuCl}$ in which the bending angle was $180^{\circ}$. A comparison of the bending angle of the theoretical structures of $\mathrm{Au} 1-\mathrm{NHC}_{\mathrm{H}}-\mathrm{Au} 1$ $\mathrm{NHGe}_{\mathrm{H}}$ indicates that our calculated values are quite similar (Boehme \& Frenking 1998). In contrast to that the bending angle of Aul-NHE 


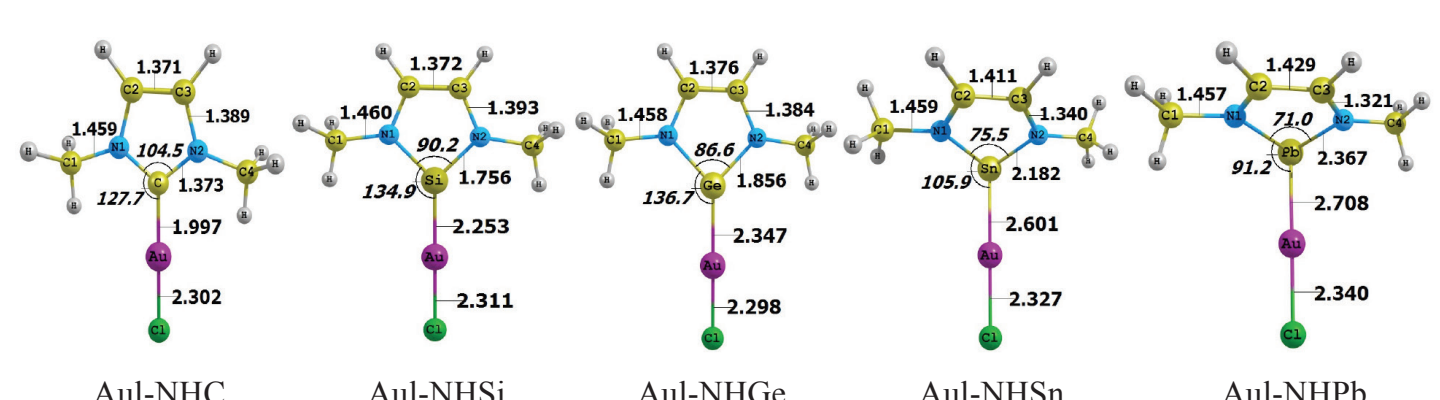

Figure 1. Optimized geometries of complexes Au1-NHC-Au1-NHPb at the BP86/def2SVP level. Bond lengths are given in A; angles in degrees. The bending angle, $\alpha$, is the angle $X$-E-Au where $X$ is the mid-point between the $N$-N distance:

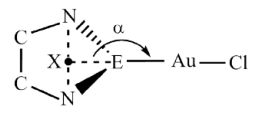

became much more acute when $\mathrm{E}$ was heavier (bending angles $\alpha$ of Au1-NHSn $=110.3^{\circ}$ and $\mathrm{Au} 1-\mathrm{NHPb}=91.5^{\circ}$ ). We want to discuss the changes in the geometries of free ligands and $\mathrm{AuCl}$ in complexes. Table 1 shows that the bond lengths E-N in the complexes increased from $\mathrm{C}-\mathrm{N}$ to $\mathrm{Pb}-\mathrm{N}$ and those were shorter than in the free ligands in which the calculated values for the free ligands $\mathrm{NHC}_{\mathrm{Me}}-\mathrm{NHPb}_{\mathrm{Me}}$ have recently been discussed by us (Nguyen et al. 2015). The increase of $\mathrm{Au}-\mathrm{Cl}$ distances from the lighter to the heavier complexes exhibits the same trend compared with the values in the AuCl-NHE $(\mathrm{E}=\mathrm{C}-\mathrm{Pb})$ complexes (Boehme \& Frenking 1998).

Table 1 also shows the calculated BDEs for the $\mathrm{Au}-\mathrm{NHE}_{\mathrm{Me}}$ bonds. There was a significant decrease from the carbene complex Au1-NHC $\left(D_{e}=79.2 \mathrm{kcal} / \mathrm{mol}\right)$ to the silylene Au1-NHSi complex $\left(D_{e}=67.0 \mathrm{kcal} / \mathrm{mol}\right)$ and continuous decrease for the BDEs of the heavier group-14 ligands $(51.9-42.7 \mathrm{kcal} / \mathrm{mol})$. The calculations suggest that the $\mathrm{NHC}_{\mathrm{Me}}$ ligand in $\mathrm{Au} 1-\mathrm{NHC}$ is the strongest bonded while the heavier homologues Au1-NHE where E = Si, Ge, Sn, $\mathrm{Pb}$ have weaker bonds which are not much different compared with the BDEs of the complexes in the previous studies (Boehme \& Frenking 1998; Nguyen \& Frenking 2012). The trend of the theoretically predicted $\mathrm{AuCl}$-carbene and analogues bond energy in this study was significantly higher than the calculated values for the borane$\mathrm{NHE}_{\mathrm{Me}}$ complexes $\left(D_{e}=59.8-13.8 \mathrm{kcal} / \mathrm{mol}\right)$ (Nguyen et al. 2015), the classical Fischer complex $(\mathrm{CO})_{5} \mathrm{~W}-\mathrm{CH}(\mathrm{OH})\left(D_{e}=75.0 \mathrm{kcal} /\right.$ mol) (Vyboishchikov \& Frenking 1998) as well as the $(\mathrm{CO})_{5} \mathrm{~W}$-carbene $\left(D_{e}=54.4 \mathrm{kcal} /\right.$ $\mathrm{mol})$ and analogues $\left(D_{e}=44.3-25.5 \mathrm{kcal} / \mathrm{mol}\right)$ $\left\{(\mathrm{CO})_{5} \mathrm{~W}-\mathrm{NHE}\right.$ with $\left.\mathrm{E}=\mathrm{C}-\mathrm{Pb}\right\}$ (Nguyen \& Frenking 2012). This was quite suitable because the metal-NHE $\mathrm{Me}_{\mathrm{Me}}$ interactions of $\mathrm{NHE}_{\mathrm{Me}}-\mathrm{AuCl}$ had small $\mathrm{NHE}_{\mathrm{Me}} \leftarrow \mathrm{AuCl} \pi$-back-donation in complexes. From this, it follows that the monoaurated donor-acceptor complexes with carbene, silylene, and germylene ligands could have very strong bonds and the appearance of a small contribution in free ligands $\leftarrow \mathrm{AuCl}$ $\pi$-back-donation in complexes would be further explained in bonding analysis.

\section{Analysis of the Bonding Situation}

The bonding situation in the complexes Au1-NHC-Au1-NHPb was analyzed using charge- and energy-decomposition methods. Table 2 shows the results of the NBO partitioning scheme and the Wiberg bond indices as well as the natural partial charges. The calculated partial charges showed that the metal fragment $\mathrm{AuCl}$ in the complexes carried always a negative charge which increases from Aul-NHC (-0.31 e) to Au1-NHPb (-0.53 e). 
Table 1: Bond length $(A)$, bond angle $\left({ }^{\circ}\right)$, and bending angle $\left(\alpha^{\circ}\right)$ for the optimized neutral molecules of Au1-NHC-Au1-NHPb calculated at the BP86/def2-SVP level, and calculated bond dissociation energy,

$D_{e}(\mathrm{kcal} / \mathrm{mol})$ for the dissociation of one molecule of $\mathrm{AuCl}$ from Au1-NHC to Au1-NHPb at the BP86/ def2-TZVPP//BP86/def2-SVP level of theory.

\begin{tabular}{|c|c|c|c|c|}
\hline Molecule & Bonding $(\AA)$ & Bonding angle $\left(^{\circ}\right)$ & Bending angle $\left(\alpha^{\circ}\right)$ & $D_{e}(\mathrm{kcal} / \mathrm{mol})$ \\
\hline Au1-NHC & $\begin{array}{c}\mathrm{C}-\mathrm{Au}=1.997 \\
\mathrm{C}-\mathrm{N}=1.373 \\
\mathrm{Au}-\mathrm{Cl}=2.302\end{array}$ & $\begin{array}{l}\mathrm{N} 1 \mathrm{CN} 2=104.5 \\
\mathrm{~N} 1 \mathrm{CAu}=127.7\end{array}$ & 180.0 & 79.2 \\
\hline Au1-NHSi & $\begin{array}{c}\mathrm{Si}-\mathrm{Au}=2.253 \\
\mathrm{Si}-\mathrm{N}=1.756 \\
\mathrm{Au}-\mathrm{Cl}=2.311\end{array}$ & $\begin{array}{c}\mathrm{N} 1 \mathrm{SiN} 2=90.2 \\
\mathrm{~N} 1 \mathrm{SiAu}=134.9\end{array}$ & 180.0 & 67.0 \\
\hline Au1-NHGe & $\begin{array}{c}\mathrm{Ge}-\mathrm{Au}=2.347 \\
\mathrm{Ge}-\mathrm{N}=1.856 \\
\mathrm{Au}-\mathrm{Cl}=2.298\end{array}$ & $\begin{array}{c}\mathrm{N} 1 \mathrm{GeN} 2=86.6 \\
\mathrm{~N} 1 \mathrm{GeAu}=136.7\end{array}$ & 180.0 & 51.9 \\
\hline Au1-NHSn & $\begin{array}{c}\mathrm{Sn}-\mathrm{Au}=2.601 \\
\mathrm{Sn}-\mathrm{N}=2.182 \\
\mathrm{Au}-\mathrm{Cl}=2.327\end{array}$ & $\begin{array}{c}\mathrm{N} 1 \mathrm{SnN} 2=75.5 \\
\mathrm{~N} 1 \mathrm{SnAu}=105.9\end{array}$ & 110.3 & 44.2 \\
\hline $\mathrm{Au} 1-\mathrm{NHPb}$ & $\begin{array}{c}\mathrm{Pb}-\mathrm{Au}=2.708 \\
\mathrm{~Pb}-\mathrm{N}=2.367 \\
\mathrm{Au}-\mathrm{Cl}=2.340\end{array}$ & $\begin{array}{l}\mathrm{N} 1 \mathrm{PbN} 2=71.0 \\
\mathrm{~N} 1 \mathrm{PbAu}=91.2\end{array}$ & 91.5 & 42.7 \\
\hline
\end{tabular}

Table 2. NBO results with Wiberg bond indices (WBI) and natural population analysis (NPA) at the BP86/def2-TZVPP// BP86/def2-SVP level for complexes Au1-NHC $\mathrm{Au} 1-\mathrm{NHPb}$. The partial charges, q, are given in electrons [e].

\begin{tabular}{|c|c|c|c|c|c|}
\hline Molecule & Bond & WBI & $q[\mathrm{AuCl}]$ & Atom & $\operatorname{NPA}(q)$ \\
\hline \multirow[t]{3}{*}{ Au1-NHC } & $\mathrm{Au}-\mathrm{C}$ & 0.70 & -0.31 & $\mathrm{Au}$ & 0.22 \\
\hline & C-N1 & 1.25 & & $\mathrm{C}$ & 0.13 \\
\hline & $\mathrm{C}-\mathrm{N} 2$ & 1.25 & & $\mathrm{~N}$ & -0.31 \\
\hline \multirow[t]{3}{*}{ Au1-NHSi } & $\mathrm{Au}-\mathrm{Si}$ & 0.88 & -0.43 & $\mathrm{Au}$ & 0.10 \\
\hline & Si-N1 & 0.82 & & $\mathrm{Si}$ & 1.16 \\
\hline & Si-N2 & 0.82 & & $\mathrm{~N}$ & -0.71 \\
\hline \multirow[t]{3}{*}{ Aul-NHGe } & $\mathrm{Au}-\mathrm{Ge}$ & 0.75 & -0.37 & $\mathrm{Au}$ & 0.14 \\
\hline & Ge-N1 & 0.80 & & $\mathrm{Ge}$ & 1.07 \\
\hline & Ge-N2 & 0.80 & & $\mathrm{~N}$ & -0.68 \\
\hline \multirow[t]{3}{*}{ Au1-NHSn } & $\mathrm{Au}-\mathrm{Sn}$ & 0.62 & -0.47 & $\mathrm{Au}$ & 0.04 \\
\hline & Sn -N1 & 0.61 & & $\mathrm{Sn}$ & 0.86 \\
\hline & $\mathrm{Sn}-\mathrm{N} 2$ & 0.61 & & $\mathrm{~N}$ & -0.56 \\
\hline \multirow[t]{3}{*}{ Au1-NHPb } & $\mathrm{Au}-\mathrm{Pb}$ & 0.61 & -0.53 & $\mathrm{Au}$ & -0.01 \\
\hline & $\mathrm{Pb}-\mathrm{N} 1$ & 0.49 & & $\mathrm{~Pb}$ & 0.74 \\
\hline & $\mathrm{Pb}-\mathrm{N} 2$ & 0.49 & & $\mathrm{~N}$ & -0.49 \\
\hline
\end{tabular}


The amount of charge donation to the $\mathrm{AuCl}$ fragment is always smaller than the donation to other transition metal moieties such as $\mathrm{W}(\mathrm{CO})_{5}$ and $\mathrm{Mo}(\mathrm{CO})_{4}$ that carry the similar $\mathrm{NHE}_{\mathrm{Me}}$ ligands in the complexes which have been calculated in the previous papers (Nguyen \& Frenking 2012; Nguyen et al. 2014a; Nguyen et al. 2014b) in which the more negative charges in transition metal fragments $\mathrm{W}(\mathrm{CO})_{5}$ and $\mathrm{Mo}(\mathrm{CO})_{4}$ are between -0.47 and -0.77 e from the lighter to the heavier homologues.

The Wiberg bond orders for the Au-E bond in Au1-NHC was 0.70 and increased in the Aul-NHSi (0.88) and then decreased from $\mathrm{Au} 1-\mathrm{NHGe}$ to $\mathrm{Au} 1-\mathrm{NHPb}$ which were from 0.75 to 0.61 . The bond order for the E-N bond became clearly larger in the complexes Au1-NHC-Au1-NHPb compared with the free ligands $\mathrm{NHC}_{\mathrm{Me}}-\mathrm{NHPb}_{\mathrm{Me}}$. This is in agreement with the change in the E-N bonds which become shorter in the complexes than in the free ligands (Nguyen 2015; Nguyen et al. 2014b). The natural population analysis carried out for complexes found that the electrostatic charges of carbon atom in the $\mathrm{NHC}_{\mathrm{Me}}$ fragment of Au1NHC complex was nearly neutral whereas $\mathrm{Si}$ and Ge carried large positive charges which were 1.16 and $1.07 \mathrm{e}$ and then slightly decreased in the heavier homologues $(\mathrm{Sn}=0.86 \mathrm{e}$ and $\mathrm{Pb}$ $=0.74 \mathrm{e}$ ).

As mentioned in the computational methods, all complexes were considered under without any symmetry constraints meant the molecules had C1 symmetry. So there were no genuine $\sigma$ and $\pi$ orbitals because there was no mirror plane in the molecular structure. Although the lighter complexes Au1-NHE exhibited the end-on bonded in the $\mathrm{NHE}_{\mathrm{Me}}$ ligands $(\mathrm{E}=\mathrm{C}-\mathrm{Ge})$ whereas the heavier ligands $\mathrm{NHSn}_{\mathrm{Me}}$ and $\mathrm{NHPb}_{\mathrm{Me}}$ were bonded side-on to the metal fragment $\mathrm{AuCl}$. In order to consider the strength of the $\pi$ donation $\mathrm{NHE}_{\mathrm{Me}} \rightarrow \mathrm{AuCl}$ which might be expected from the $\sigma$ - and $\pi$ lonepair orbital of the ligand $\mathrm{NHE}_{\mathrm{Me}}$ into the second vacant coordination side of metal fragment $\mathrm{AuCl}$, we had to visually keep the shapes of $\mathrm{Au} 1-\mathrm{NHSn}$ and $\mathrm{Au} 1-\mathrm{NHPb}$ in one plane to identify $\sigma$ - and $\pi$-type molecular orbitals. Figure 2 shows two occupied molecular orbitals and orbital energies of $\sigma$-type and $\pi$-type MOs from Au1-NHC-Au1-NHPb at the BP86/ TZVPP level. The energy levels of the $\pi$-type donor orbitals of complexes were higher lying than the $\sigma$-type donor orbitals. The orbital energy values were particularly large in the Aul-NHC in both $\sigma$ - and $\pi$-type MOs and decreased in the silylene and germylene as well as in the heavier analogues. Especially, the shape of the molecular orbitals which indicated that $\mathrm{NHE}_{\mathrm{Me}} \rightarrow \mathrm{AuCl}$ not only had significant $\sigma$ donation but also exhibited a bit $\pi$ donation in complexes. We can explain that the $\pi$ donation in complexes due to the strong $\mathrm{N} \rightarrow \mathrm{E} \pi$ donation at the ring of the $\mathrm{NHE}_{\mathrm{Me}}$ ligands.

We showed the frontier orbitals with the plot of the energy levels of the energetically highest lying $\sigma$ and $\pi$ orbital of the isolated NHE ligands (Figure 3) in order to know whether the ligands had an occupied $\pi$-orbital in the E center atom. The HOMO of NHE ligand had $\pi$ symmetry, except for NHC, in which the HOMO has $\sigma$ symmetry whereas the HOMO-1 and HOMO-2 had $\pi$ symmetry. The $\sigma$ orbitals of NHE ligand were uniformly lone-pair molecular orbitals (MOs), but the $\pi$ orbitals were delocalized over the NHE ring atoms. Figure 3 also shows that the energy level of the $\pi$ orbital increased, whereas that of the $\sigma$ orbital decreased as atom $E$ became heavier. The trend of the energy levels of the energetically highest-lying $\sigma$ and $\pi$ orbitals of NHE ligand rationalize the preference of the heavier ligands $\mathrm{NHSn}$ to $\mathrm{NHPb}$ for side-on co-ordination to the metal, in which the $\sigma$-donation takes place through the $\pi$ orbital of the ligand (Nguyen \& Frenking 2012). The end-on coordination of the lighter homologues NHC to NHGe could be explained by various factors that also influence the bending angle $\alpha$ of the ligands (Table 1). 


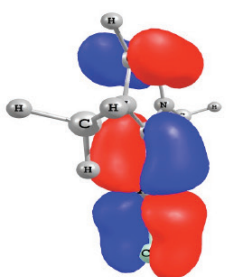

$\operatorname{Aul}-\mathrm{NHC}(\pi)$

HOMO-6

$-7.157(\mathrm{eV})$

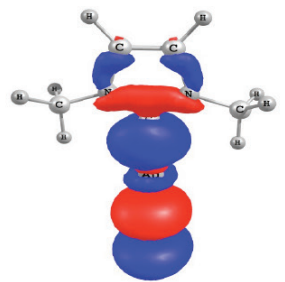

$\operatorname{Aul}-\mathrm{NHC}(\sigma)$

HOMO-9

$-8.136(\mathrm{eV})$

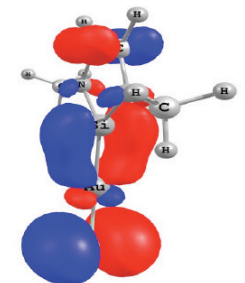

Aul-NHSi $(\pi)$

HOMO-2

$-6.150(\mathrm{eV})$

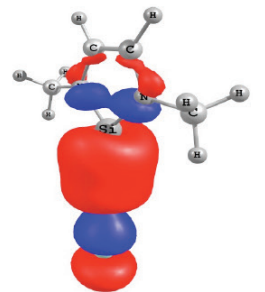

Aul-NHSi ( $\sigma$ )

HOMO-5

$-7.460(\mathrm{eV})$

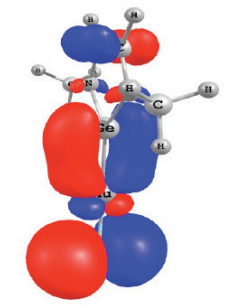

Aul-NHGe $(\pi)$

HOMO-2

$-6.123(\mathrm{eV})$

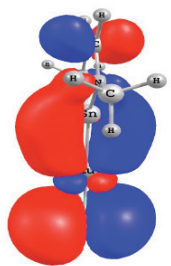

Aul-NHSn $(\pi)$

HOMO-2

$-5.660(\mathrm{eV})$

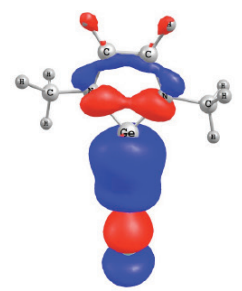

Aul-NHGe $(\sigma)$

HOMO-7

$-7.674(\mathrm{eV})$

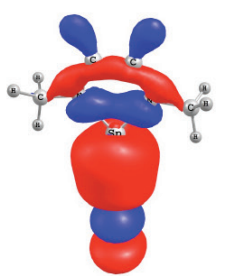

Aul-NHSn ( $\sigma)$

HOMO-6

$-7.320(\mathrm{eV})$

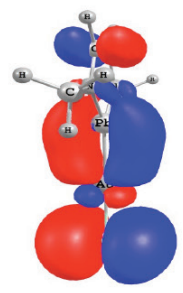

Aul-NHPb $(\pi)$

HOMO-2

$-5.361(\mathrm{eV})$

Figure 2. Molecular orbitals and orbital energies of $\sigma$-type and $\pi$-type $M O$ s from Aul-NHC-Aul-NHPb at the BP86/TZVPP level. Orbital energies are given in $\mathrm{eV}$.

We also want to point out the orbitals at the Au side carried a little $\mathrm{NHE}_{\mathrm{Me}} \leftarrow \mathrm{AuCl}$ backdonation and mainly exhibited $\mathrm{NHE}_{\mathrm{Me}} \rightarrow \mathrm{AuCl}$ $\sigma$-donation. We suggested the scheme illustration showing the mixing of the empty $s$ and occupied $d_{z}^{2}$ orbitals of $\mathrm{Au}(\mathrm{I})$ which was graphically shown in Figure $4 a$. Note that the Au cation had an $s^{0} d^{10}$ electron configuration but the $s$ orbital was mostly filled in $\mathrm{AuCl}$ due to the ionic $\mathrm{Au}^{+}-\mathrm{Cl}^{-}$bond and the lowest lying empty orbitals were at the Au might be $p$ orbitals. Although in the gold(I) complex, the relativistic effects were responsible for the very small charge transfer from $\mathrm{Au}$ to $\mathrm{Cl}$ but when the $\mathrm{AuCl}-\mathrm{NHE}_{\mathrm{Me}}$ was formed, there was no further charge transfer from the Au atom to chlorine. From this it could be asserted that there was the mixing of the valence s orbital with occupied $d_{z}^{2}$ orbital of the $\mathrm{Au}$. The competition for the empty Au $s$ orbital between donation from chlorine and the carbene-analogues $\sigma$-lone pair might lead to the longer $\mathrm{Au}-\mathrm{Cl}$ bonds in the complexes (Figure 1).

Furthermore, the three filled orbitals arose from the $\mathrm{E}$ atom to $\mathrm{Au}$ and to $\mathrm{Cl}(\mathrm{E}-\mathrm{Au}-\mathrm{Cl})$ $\sigma$-interactions which were illustrated in Figure $4 b$. The highest energy had $d_{z}^{2}$ symmetry along the $\mathrm{Au}-\mathrm{Cl}$ axis which could be considered as $\sigma$-antibonding character toward chlorine. The middle level of energy showed an anti-state combination of the $\mathrm{Cl} p_{z}$ and an $s p_{2}$ hybrid on the $\mathrm{E}$ atom and also revealed that there was no bonding toward $\mathrm{Au}$. The lowest energy of $\mathrm{E}-\mathrm{Au}-\mathrm{Cl} \sigma$-bonding orbitals exhibited a constructive overlap of the $\mathrm{Au}(\mathrm{I}) 5 d_{z}^{2}$ orbital that carried the $\sigma$-symmetry on $\mathrm{Cl}$ and $\mathrm{E}$ atoms. We could point out that the covalent part of the metal bonding in AuCl-NHE $\mathrm{Me}_{\mathrm{Me}}$ had the patent of the familiar 6-electron-3 center interactions with the fully important $d_{z}^{2}$ orbital which significantly contributed to the $\mathrm{Au}-\mathrm{Cl}$ 


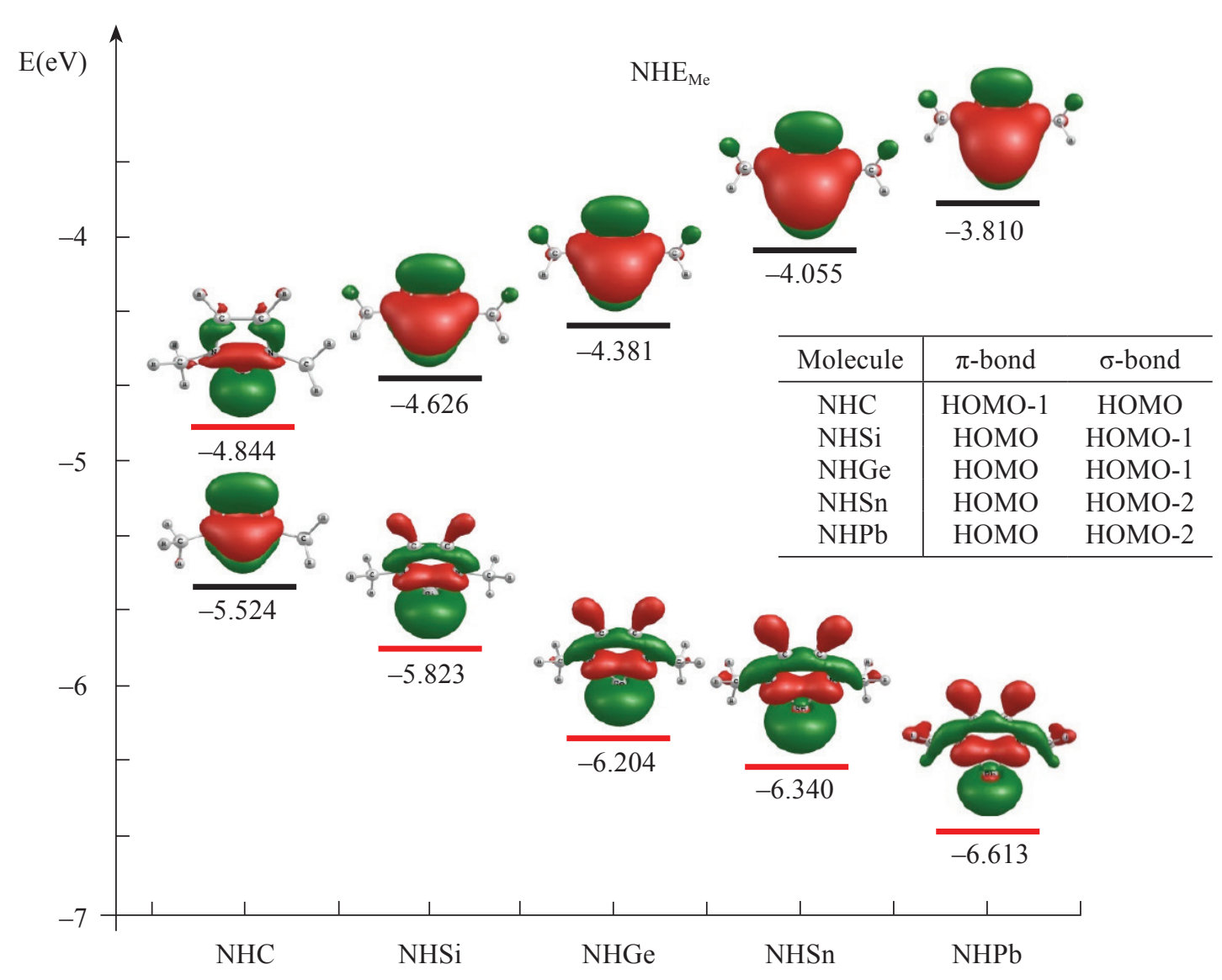

Figure 3. Plot of the energy levels of the energetically highest lying $\sigma$ and $\pi$ orbital of ligands $N H E(E=C-P b)$.

and AuCl-NHE $\mathrm{Me}_{\mathrm{Me}}$ bonding (Figure $4 b$ ). Note that the transition metal complexes $\mathrm{MCl}$ with $\mathrm{M}=\mathrm{Au}, \mathrm{Ag}, \mathrm{Cu}$ that carry the less bulky NHC ligand has been recently described by Nemcsok et al. (2004) using EDA method. In this study, we used the EDA-NOCV calculations in order to give a thorough insight into the nature of the metal-ligand bonding in Au1-NHE. This led to a donor-acceptor description of the Au-E bond in the system. Table 3 showed the results of EDA-NOCV when considering $\mathrm{NHC}_{\mathrm{Me}}$ as the donor fragments and $\mathrm{AuCl}$ as the acceptor fragment. Table 3 shows that EDA-NOCV results at the $\mathrm{BP} 86 / \mathrm{TZ} 2 \mathrm{P}+$ level for compound $\mathrm{Au} 1-\mathrm{NHC}-\mathrm{Au} 1-\mathrm{NHPb}$ using the moieties $[\mathrm{AuCl}]$ and $\left[\mathrm{NHE}_{\mathrm{Me}}\right]$ as interacting fragments.
The Au-E bond dissociation energies trend in Au1-NHE decreased from the lighter to the heavier homologues (Au1-NHC: $D_{e}=78.1 \mathrm{kcal} /$ mol; Au1-NHPb: $\left.D_{e}=42.6 \mathrm{kcal} / \mathrm{mol}\right)$.

The trend of the bond dissociations energies (BDEs) $D_{e}$ for the Au-E bond in Au1-NHE system was Aul-NHC > Au1-NHSi > Au1$\mathrm{NHGe}>\mathrm{Au} 1-\mathrm{NHSn}>\mathrm{Au} 1-\mathrm{NHPb}$. The decrease of the BDEs from the lighter to heavier adduct was determined by the intrinsic strength of the Au-ligand bonds $\Delta E_{\text {int }}$. The carbene adduct had a smaller preparation energy of the interacting fragments $\left(\Delta E_{\text {prep }}=1.2 \mathrm{kcal} / \mathrm{mol}\right)$ and stays nearly the same in the heavier homologues $\left(\Delta E_{\text {prep }}=2.0-2.5 \mathrm{kcal} / \mathrm{mol}\right)$ and the largest 


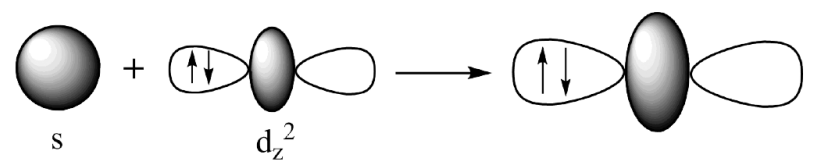

(a)

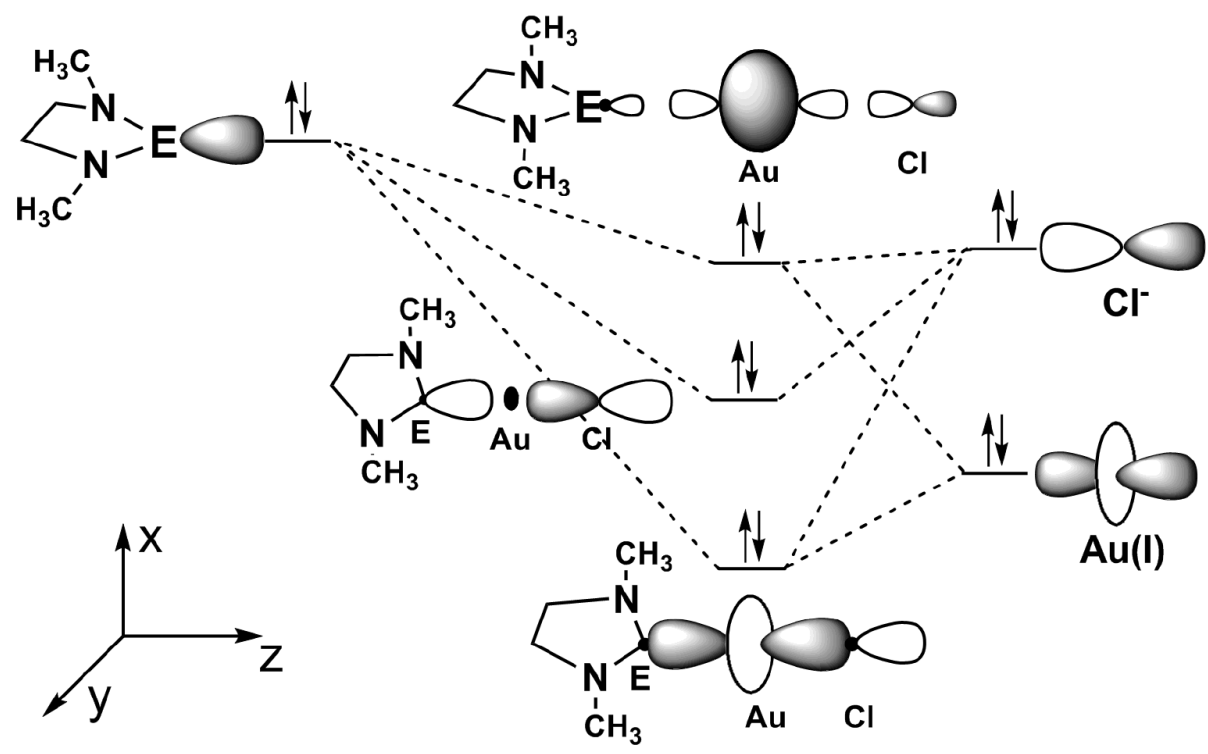

(b)

Figure 4. (a) Scheme illustration showing the mixing of the empty s and occupied $d_{z}^{2}$ orbitals of $\mathrm{Au}(I)$; (b) Qualitative diagram of the interaction of the $\mathrm{Au}^{+} \mathrm{d}_{z}{ }^{2}$ orbital with $\mathrm{Cl}$ and $\sigma$-donor orbital of $E$ atom with $E=C-P b$.

Table 3. EDA-NOCV results at the BP86/TZ2P+level for compound Au1-NHC-Au1-NHPb using the moieties $[\mathrm{AuCl}]$ and $\left[\mathrm{NHE}_{\mathrm{Me}}\right]$ as interacting fragments. The complexes are analyzed with $\mathrm{C} 1$ symmetry. Energy values in $\mathrm{kcal} / \mathrm{mol}$.

\begin{tabular}{|c|c|c|c|c|c|}
\hline $\begin{array}{l}\text { Compound } \\
\text { Fragment }\end{array}$ & $\begin{array}{c}\mathrm{Au} 1-\mathrm{NHC} \\
{[\mathrm{AuCl}]} \\
{\left[\mathrm{NHC}_{\mathrm{Me}}\right]}\end{array}$ & $\begin{array}{c}\mathrm{Au} 1-\mathrm{NHSi} \\
{[\mathrm{AuCl}]} \\
{\left[\mathrm{NHSi}_{\mathrm{Me}}\right]}\end{array}$ & $\begin{array}{c}\mathrm{Au} 1-\mathrm{NHGe} \\
{[\mathrm{AuCl}]} \\
{\left[\mathrm{NHGe}_{\mathrm{Me}}\right]}\end{array}$ & $\begin{array}{c}\text { Aul-NHSn } \\
{[\mathrm{AuCl}]} \\
{\left[\mathrm{NHSn}_{\mathrm{Me}}\right]}\end{array}$ & $\begin{array}{c}\mathrm{Au} 1-\mathrm{NHPb} \\
{[\mathrm{AuCl}]} \\
{\left[\mathrm{NHPb}_{\mathrm{Me}}\right]}\end{array}$ \\
\hline$\Delta E_{\text {int }}$ & -79.3 & -68.5 & -52.2 & -47.2 & -50.0 \\
\hline$\Delta E_{\text {Pauli }}$ & 212.1 & 186.9 & 124.9 & 95.5 & 84.8 \\
\hline$\Delta E_{\text {elstat }}^{[a]}$ & $-219.3(75.3 \%)$ & $-182.0(71.3 \%)$ & $-118.5(66.9 \%)$ & $-87.2(61.1 \%)$ & $-78.3(58.1 \%)$ \\
\hline$\Delta E_{o r b}^{\lceil a]}$ & $-72.1(24.7 \%)$ & $-73.3(28.7 \%)$ & $-58.6(33.1 \%)$ & $-55.5(38.9 \%)$ & $-56.5(41.9 \%)$ \\
\hline$\Delta E_{\sigma}^{[b]}$ & $-51.3(71.2 \%)$ & $-50.0(68.2 \%)$ & $-42.6(72.8 \%)$ & $-45.4(81.7 \%)$ & $-49.0(86.7 \%)$ \\
\hline$\Delta E_{\pi}^{[b]}$ & $-17.0(23.5 \%)$ & $-20.8(28.4 \%)$ & $-13.7(23.4 \%)$ & $-7.9(14.3 \%)$ & $-4.9(8.7 \%)$ \\
\hline$\Delta E_{\text {rest }}^{[b]}$ & $-3.8(5.3 \%)$ & $-2.5(3.4 \%)$ & $-2.3(3.8 \%)$ & $-2.2(4.0 \%)$ & $-2.6(4.6 \%)$ \\
\hline$\Delta E_{\text {prep }}$ & 1.2 & 2.4 & 2.0 & 2.5 & 7.4 \\
\hline$\Delta E\left(=-D_{e}\right)$ & $-78.1(79.2)^{[\mathrm{c}]}$ & $-66.0(67.0)^{[\mathrm{cc}]}$ & $-50.2(51.9)^{[\mathrm{c}]}$ & $-44.7(44.2)^{[c]}$ & $-42.6(42.7)^{[\mathrm{cc}]}$ \\
\hline
\end{tabular}

[a] The values in parentheses are the percentage contributions to the total attractive interaction $\Delta E_{\text {elstat }}+\Delta E_{\text {orb }}$.

[b] The values in parentheses are the percentage contributions to the total orbital interaction $\Delta E_{\text {orb }}$.

[c] The values in parentheses give the dissociation energy at the BP86/def2-TZVPP//BP86/def-SVP level. 
value preparation energy was $7.4 \mathrm{kcal} / \mathrm{mol}$ which gave the smallest BDE for Au1-NHPb. Inspection of the three main terms which contributed to the interaction energy $\Delta E_{\text {int }}$ indicated that the Pauli repulsion $\Delta E_{\text {Pauli }}$ and the electrostatic attraction $\Delta E_{\text {elstat }}$ were smaller for the heavier group-14 atoms Au1-NHSi$\mathrm{Au} 1-\mathrm{NHPb}$ than for Au1-NHC. The largest contributions to the $\Delta E_{\text {int }}$ values of the system always came from the electrostatic interaction term $\Delta E_{\text {elstat }}$ which contributed more than $60 \%$ in complexes except for the less than that in $\mathrm{Au} 1-\mathrm{NHPb}(58.1 \%)$. In contract to this, the orbital term contributed $<30 \%$ in the lighter complexes which were $24.7 \%$ and $28.7 \%$ for Au1-NHC and Au1-NHSi. The strength of the total orbital interactions $\Delta E_{\text {orb }}$ decreased from the lighter to the heavier homologues. Note that the most important information which was provided by the EDA-NOCV calculations concerned the strength of the $\sigma$ and $\pi$ bonding. Table 3 also shows that the contribution of $\Delta E_{\sigma}$ to $\Delta E_{\text {orb }}$ was rather large for all complexes where the values were between $68.2 \%-86.7 \%$. For all complexes holds that the contribution of $\Delta E_{\pi}$ to $\Delta E_{\text {orb }}$ is significantly smaller than in other transition metal complexes of tungsten pentacarbonyl and teracarbonyl complexes $\left[\mathrm{W}(\mathrm{CO})_{5}\right.$-NHE] (with $\mathrm{E}=\mathrm{C}-\mathrm{Pb}$ ) (Nguyen \& Frenking 2012). Thus, the EDA-NOCV calculations showed that the Au-E bonding in the complexes Au1-NHC-Au1-NHPb had a small contribution which might come from $\mathrm{NHE}_{\mathrm{Me}} \rightarrow \mathrm{AuCl} \pi$-donation and $\mathrm{NHE}_{\mathrm{Me}} \rightarrow \mathrm{AuCl}$ $\pi$-back-donation. We continue determining the charge transfer between the donor and acceptor fragments by plotting of the pairs of orbitals, the associated deformation densities, and stabilization energies. The fact was that, the plots of the pairs of orbitals $\psi_{k} \psi_{-k}$ that yield the NOCVs provided the largest contributions to the $\sigma$ - and $\pi$-orbital terms $\Delta E_{\sigma}$ and $\Delta E_{\pi}$ in Au1$\mathrm{NHE}(\mathrm{E}=\mathrm{C}, \mathrm{Si})$ and the associated deformation densities $\Delta \rho$ and stabilization energies were shown in Figure 5. The shape of pairs for Au1NHSi and Aul-NHGe were quite similar with the carbene complex, while the shape of pairs for the heavier specie shape of pairs for Au1NHSn possessed the same shapes compared with the shape of pairs for Au1-NHPb, and there for were not shown in Figure 5.

Note that the white/blue colours in the small figures for $\psi_{k} / \psi_{-k}$ indicated the sign of the orbitals, and the black/yellow colours in the deformation density $\Delta \rho$ designate charge depletion, and the yellow areas point to charge accumulation. The charge flow $\Delta \rho$ occurred in the direction from black to yellow. Figure 5 (a) shows that the $\sigma$-type interaction was clearly from the donating $\mathrm{NHC}_{\mathrm{Me}}$ fragment to the accepting $\mathrm{AuCl}$ fragment which was the deformation density $\Delta \rho_{l}$ which showed that stabilization of energy was $-42.0 \mathrm{kcal} /$ mol. The shapes of the NOCV pairs $\psi_{2} / \psi_{-2}$ and the deformation density $\Delta \rho_{2}$ showed that stabilization of $-11.1 \mathrm{kcal} / \mathrm{mol}$ could be assigned to $\mathrm{ClAu} \leftarrow \mathrm{NHC}_{\mathrm{Me}} \pi$-donation while the stabilization of also came from relaxation of the acceptor fragment $\mathrm{AuCl}$ in Au1-NHC. Figure 5(c,d) shows significantly different EDA-NOCV results for Aul-NHPb because of the surprising structure of the plumbylene ligand which was bonded through its $\pi$-electron density. Note that the structures and orbitals pairs of the lighter homologues Au1-NHE with $\mathrm{E}=\mathrm{C}, \mathrm{Si}$, Ge had head-on modes between the ligands and metal fragment, whereas the heavier species Au1-NHE with $\mathrm{E}=\mathrm{Sn}, \mathrm{Pb}$ exhibited a side-on bonded ligands to the $\mathrm{AuCl}$ fragment. Figure 5(c) clearly shows that the $\sigma$-type interaction had the direction of the charge flow of $\mathrm{ClAu} \leftarrow \mathrm{NHPb}_{\mathrm{Me}}$. The deformation density $\psi_{1}$ exhibited an area of charge donation (black area) at the $\mathrm{NHPb}_{\mathrm{Me}}$ moiety associated with the deformation density $\Delta \rho_{l}$ and stabilization energy was $-46.1 \mathrm{kcal} / \mathrm{mol}$. Figures $5(d)$ show that the very weak $\pi$-type orbital interactions in Au1-NHPb came from typical $\pi$-back-donation $\mathrm{ClAu} \rightarrow \mathrm{NHPb}_{\mathrm{Me}}$ with the charge flow $\psi_{2} / \psi_{-2}$ which indicated stabilization at $-2.9 \mathrm{kcal} / \mathrm{mol}$. Thus, the bonding in Au1-NHE complexes exhibited the typical feature in terms of strong $\sigma$-donation and weak $\pi$-back-donation. From 
(a)

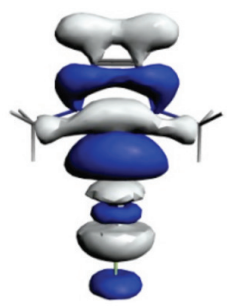

$\psi_{-1}(-0.56)$

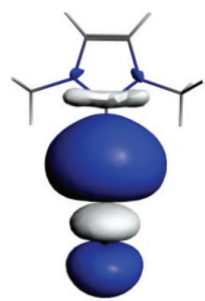

Aul-NHC $(\sigma)$

$\psi_{1}(0.56)$

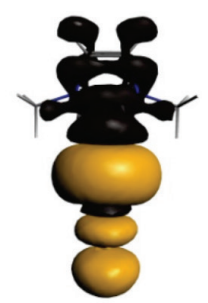

$\Delta \rho_{1}(\Delta \mathrm{E}=-42.0)$

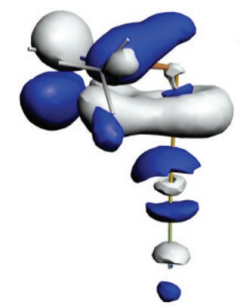

Aul-NHPb ( $\sigma)$

(c)

(b)

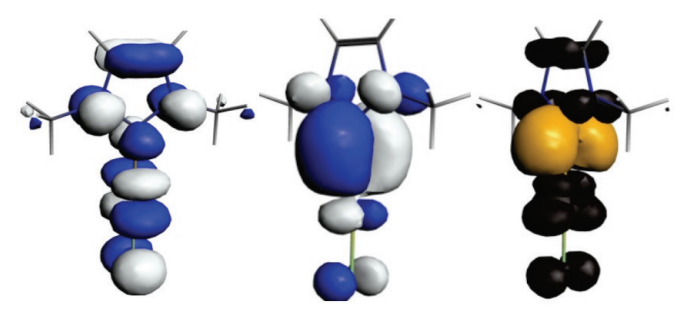

Aul-NHC $(\pi)$

$\psi_{-2}(-0.36)$

$\psi_{2}(0.36)$

$\Delta \rho_{2}(\Delta \mathrm{E}=-11.1)$ $\psi_{-1}(-0.81)$

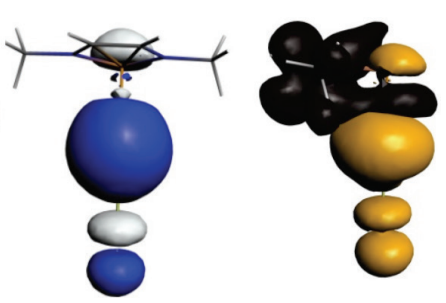

$\psi_{1}(0.81)$

$\Delta \rho_{1}(\Delta \mathrm{E}=-46.1)$ (d)

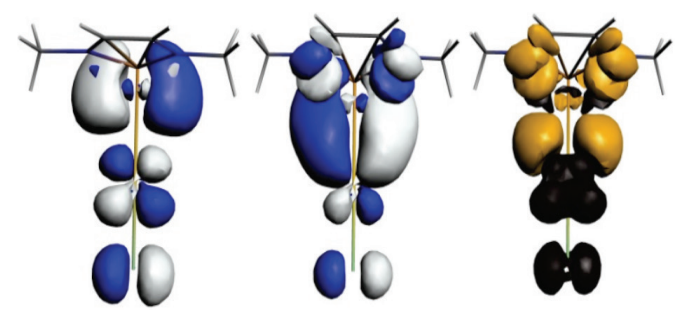

$\operatorname{Aul}-\mathrm{NHPb}(\pi)$

$\psi_{-2}(-0.26)$
$\Delta \rho_{2}(\Delta \mathrm{E}=-2.9)$

Figure 5. Most important NOCV pairs of orbitals $\Psi_{-k}, \Psi_{k}$ with their eigenvalues $-v_{k}, v_{k}$ given in parentheses, and the associated deformation densities $\Delta \rho_{k}$ and orbital stabilization energies $\Delta E$ for the complexes Aul-NHC and Aul-NHPb. The charge flow in the deformation densities is from the black $\rightarrow$ yellow region. (a) $\sigma-N O C V$ of Aul-NHC; (b) $\pi-N O C V$ of Au1-NHC; (c) $\sigma-N O C V A u 1-N H P b$;

(d) $\pi-N O C V$ of Aul-NHPb. Energy values in kcal/mol.

the above results, it could be asserted that the decrease in the donation $\mathrm{ClAu} \leftarrow \mathrm{NHE}_{\mathrm{Me}}$ which was manifested in the calculated values for $\Delta E_{\sigma}$ and in the electrostatic attraction, $\Delta E_{\text {elstat }}$, provided a rationale for the weaker bonding of the heavier atoms $\mathrm{E}$. The $\pi$-interactions in $\left[\mathrm{ClAu}-\mathrm{NHE}_{\mathrm{Me}}\right]$ were due to very weak $\pi$-backdonation and were also irrelevant for the bond strength. The ligand $\leftarrow \mathrm{Au} \pi$-back-donation in the complexes was very small and the Au-ligand bonds had strong ionic character which came from the electrostatic attraction between the positively charged $\mathrm{Au}$ atom and the $\sigma$-electron pair of the E donor atom.

\section{CONCLUSIONS}

In summary, the full isolable carbene analoguesstablized gold(I) chloride was structurally characterized in this work. DFT calculations found that the equilibrium structures of the Au1-NHE system showed major differences in the bonded orientation from the ligands $\mathrm{NHC}$ to NHPb of gold(I) complex between the lighter and the heavier homologues. The calculated structures of carbene-analogues complexes Au1-NHE of the lighter complexes Au1-NHE possessed end-on-bonded $\mathrm{NHE}_{\mathrm{Me}}$ ligands $(\mathrm{E}=\mathrm{C}-\mathrm{Ge})$ with the bending angles, $\alpha$, were $180^{\circ}$. In contrast, the heavier species 
Au1-NHSn and Au1-NHPb exhibit side-onbonded ligands which the bending angle, $\alpha$, became more acute $\left(110.3^{\circ}\right.$ for Aul-NHSn and $91.5^{\circ}$ for $\left.\mathrm{Au} 1-\mathrm{NHPb}\right)$. The trend of the bond dissociation energy of Au-ligands in Au1-NHE show for the ligands NHE order is: Au1-NHC > Aul-NHSi $>$ Au1-NHGe $>$ Au1-NHSn $>$ Au1$\mathrm{NHPb}$. Bonding analysis of Au1-NHE showed that NHE ligands exhibited donor- acceptor bonds with the $\sigma$ lone pair electrons of NHE donated into the vacant orbital of the acceptor fragment $(\mathrm{AuCl})$. The EDA-NOCV results indicated that the ligand NHE in Aul-NHE complexes were strong $\sigma$-donors and very weak $\pi$ donors. The Au-NHE bonds were mainly held together by electrostatic energy, which contributed $>60 \%$ of the binding interactions for the lighter homologues (Au1-NHC - Au1NHGe). The NOCV pairs of the bonding showed small $\pi$-back donation from the Au to the NHE ligands.

\section{ACKNOWLEDGEMENTS}

This research was funded by Vietnam National Foundation for Science and Technology Development (NAFOSTED) under grant number 104.06-2014.13 (Nguyen Thi Ai Nhung). The jobs of this study were run via Erwin cluster which is an excellent service provided by the Hochschulrechenzentrum of the Philipps-Universität Marburg-Germany. N.T.A.Nhung would like to thank Prof Gernot Frenking for allowing to continuously use her own allocation at Frenking's Group. Further computer time was provided by the HLRS Stuttgart, the HHLRZ Darmstadt, and the CSC Frankfurt.

Date of submission: July 2015

Date of acceptance: August 2015

\section{REFERENCES}

Ahlrichs, R, Bär, M, Häser, M, Horn, H \& Kölmel, C 1989, 'Electronic structure calculations on workstation computers: the program system
Turbomole', Chem. Phys. Lett., vol. 162, pp. 165-169.

Arduengo, III, AJ, Kline, M, Calabrese, JC \& Davidson, F 1991, 'Synthesis of a reverse ylide from a nucleophilic carbene', J. Am. Chem. Soc., vol. 113, pp. 9704-9705.

Becke, AD 1998, 'Density-functional exchangeenergy approximation with correct asymptotic behavior', Phys. Rev. A, vol. 38, pp. 3098-3100.

Boehme, C \& Frenking, G 1998, 'N-Heterocyclic carbene, silylene, and germylene complexes of $\mathrm{MCl}(\mathrm{M}=\mathrm{Cu}, \mathrm{Ag}, \mathrm{Au})$, a theoretical study, Organometallics, vol. 17, pp. 5801-5809.

Bourissou, D, Guerret, O, Gabbaï, FP \& Bertrand, G 2000, 'Stable carbenes', Chem. Rev., vol. 100, pp. 39-91.

Bovio, B, Burini, A \& Pietroni, BR 1993, 'Reactions of trimeric 1-benzyl-2-gold(I)imidazole leading to $\mathrm{Au}^{\mathrm{I}}$ carbene complexes. Crystal structure of [1-benzyl-3-benzoyl-imidazolin-2-yliden] chlorogold(I)', J. Organomet. Chem., vol. 452, pp. 287-291.

Fischer, EO \& Maasböl, A 1964, 'On the existence of a tungsten carbonyl carbene complex', Angew. Chem. Int. Ed. Engl., vol. 3, pp. 580-581.

Frisch, MJ et al. 2004, Gaussian 03, Revision D.01, Gaussian Inc. Wallingford, CT.

Hahn, FE \& Jahnke, MC 2008, 'Heterocyclic carbenes: synthesis and coordination chemistry', Angew. Chem. Int. Ed., vol. 47, pp. 3122-3172.

Herrmann, WA 2002, 'N-Heterocyclic carbenes: a new concept in organometallic catalysis', Angew. Chem. Int. Ed., vol. 41, pp. 1290-1309.

$\mathrm{Hu}, \mathrm{X}$, Castro-Rodriguez, I, Olsen, K \& Meyer, K 2004, 'Group 11 metal complexes of n-heterocyclic carbene ligands: nature of the metal-carbene bond', Organometallics, vol. 23, pp. 755-764.

Jacobsen, H, Correa, A, Poater, A, Costabile, C \& Cavallo, L 2009, 'Understanding the M - (NHC) (NHC=N-heterocyclic carbene) bond', Coord. Chem. Rev., vol. 253, pp. 687-703.

Krijn, J \& Baerends, EJ 1984, Fit Functions in the HFS-Method, Internal Report (in Dutch), Vrije Universiteit Amsterdam, The Netherlands.

Lee, M-T \& Hu, C-H 2004, 'Density functional study of N- heterocyclic and diamino carbene 
complexes: comparison with phosphines', Organometallics, vol. 23, pp. 976-983.

Lenthe, E, van, Baerends, EJ \& Snijders, JG 1993, 'Relativistic regular two-component Hamiltonians', J. Chem. Phys., vol. 99, pp. 4597-4610.

Lenthe, E, van, Leeuwen, R, van, Baerends, EJ \& Snijders, JG 1996, 'Relativistic regular twocomponent Hamiltonians', Int. J. Quantum. Chem., vol. 57, pp. 281-293.

Marion, N \& Nolan, SP 2008, 'N-Heterocyclic carbenes in gold catalysis', Chem. Soc. Rev., vol. 37, pp. 1776-1782.

Mitoraj, M \& Michalak, A 2007a, 'Donor-acceptor properties of ligands from natural orbitals for chemical valence', Organometallics, vol. 26, pp. 6576-6580.

Mitoraj, M \& Michalak, A 2007b, 'Natural orbitals for chemical valence as description of chemical bonding in transition metal complexes', J. Mol. Model., vol. 13, pp. 347-355.

Mitoraj, M, Michalak, A \& Ziegler, T 2009, 'A combined charge and energy decomposition scheme for bond analysis', J. Chem. Theory Comput., vol. 5, pp. 962-975.

Morokuma, K 1971, 'Molecular orbital studies of hydrogen bonds. III. $\mathrm{C}=\mathrm{O}$... $\mathrm{H}-\mathrm{O}$ hydrogen bond in $\mathrm{H}_{2} \mathrm{CO} \ldots \mathrm{H}_{2} \mathrm{O}$ and $\mathrm{H}_{2} \mathrm{CO} \ldots 2 \mathrm{H}_{2} \mathrm{O}$ ', J. Chem. Phys., vol. 55, pp. 1236.

Nemcsok, D, Karin, W \& Frenking, G 2004, 'The significance of $\pi$ interactions in group 11 complexes with N-heterocyclic carbenes, Organometallics, vol. 23, pp. 3640-3646.

Nguyen, TAN et al. 2014b, 'Natural bond orbital analysis of molecular interactions: theoretical study of $\mathrm{W}(\mathrm{CO})_{5}$ complexes with $\mathrm{E}\left(\mathrm{PH}_{3}\right)_{2}$ and $\mathrm{NHE}_{\mathrm{Me}}$ ligands $(\mathrm{E}=\mathrm{C}-\mathrm{Pb})$, , Vietnam Journal of Chemistry, vol. 52, pp. 576-583.

Nguyen, TAN et al. 2014a, 'Quantum chemical investigation for structures and bonding analysis of molybdenum tetracarbonyl complexes with N-heterocyclic carbene and analogues: helpful information for plant biology research', J. Viet. Env., vol. 6, pp. 142-149.

Nguyen, TAN et al. 2015, 'Differences and similarities of structures, bond dissociation energy, and molecular orbitals of borane complexes with tetrylone and tetrylene ligands: do divalent
tetrylenes(II) have hidden divalent tetrylones(0) chemistry character? Malaysian Journal of Chemistry, vol. 17, pp. 45-57.

Nguyen, TAN \& Frenking, G 2012, 'Transitionmetal complexes of tetrylones $\left[(\mathrm{CO})_{5} \mathrm{~W}-\mathrm{E}\left(\mathrm{PPh}_{3}\right)_{2}\right]$ and tetrylenes $\left[(\mathrm{CO})_{5} \mathrm{~W}-\mathrm{NHE}\right](\mathrm{E}=\mathrm{C}-\mathrm{Pb})$ : a theoretical study', Chemistry-A European Journal, vol. 18, pp. 12733-12748.

Nolan, SP 2011, 'The development and catalytic uses of N-heterocyclic carbene gold complexes', Acc. Chem. Res., vol. 44, pp. 91-100.

Öfele, K 1968, '1,3-Dimethyl-4-imidazolinyliden-(2)pentacarbonylchrom ein neuer übergangsmetallcarben-komplex', Journal of Organometallic Chemistry, vol. 12, pp. 42-43.

Perdew, JP 1986, 'Density-functional approximation for the correlation energy of the inhomogeneous electron gas', Phys. Rev. B., vol. 33, pp. 88228824

Poater, A, Cosenza, B, Correa, A, Giudice, S, Ragone, F, Scarano, V \& Cavallo, L 2009, 'SambVca: a web application for the calculation of the buried volume of N-heterocyclic carbene ligands', Eur. J. Inorg. Chem., pp. 1759-1766.

Schäfer, A, Horn, H \& Ahlrichs, R 1992, Fully optimized contracted gaussian basis sets for atoms Li to $\mathrm{Kr}^{6}$, J. Chem. Phys., vol. 97, pp. 2571-2577.

Schwarz, J, Böhm, VPW, Gardiner, MG, Grosche, M, Herrmann, WA, Hieringer, W \& RaudaschlSieber, G 2000, 'Polymer-supported carbene complexes of palladium: well-defined, air-stable, recyclable catalysts for the Heck reaction', Chem. Eur. J., vol. 6, pp. 1773-1780.

Snijders, JG, Vernoojs, P \& Baerends, EJ 1981, 'Roothaan-Hartree-Fock-Slater atomic wave functions: single-zeta, double-zeta, and extended Slater-type basis sets for ${ }_{87} \mathrm{Fr}_{-103} \mathrm{Lr}$, At. Data Nucl. Data Tables, vol. 26, pp. 483-509.

Velde, G et al. 2001, 'Chemistry with ADF', $J$. Comput. Chem., vol. 22, pp. 931-967.

Vyboishchikov, SF \& Frenking, G 1998, 'Structure and bonding of low-valent (Fischer-type) and high-valent (Schrock-type) transition metal carbene complexes', Chem,-Eur. J., vol. 4, pp. $1428-1438$.

Wanzlick, H-W \& Schönherr H-J 1968, 'Direct synthesis of a mercury salt-carbene complex', Angew. Chem. Int. Ed. Engl., vol. 7, pp. 141-142. 
Weigend, F \& Ahlrichs, R 2005, 'Balanced basis sets of split valence, triple zeta valence and quadruple zeta valence quality for $\mathrm{H}$ to $\mathrm{Rn}$ : design and assessment of accuracy', Phys. Chem. Chem. Phys., vol. 7, pp. 3297-3305.

Weskamp, T, Kohl, FJ, Hieringer, W, Gleich, D \& Herrmann, WA 1999, 'Hochaktive Rutheniumkatalysatoren für die Olefinmetathese: die Synergie N-heterocyclischer carbene und koordinativ labiler liganden', Angew. Chem., vol. 111, pp. 2573-2576.

Zhu, S, Liang, R \& Jiang, H 2012, 'A direct and practical approach for the synthesis of $\mathrm{N}$-heterocyclic carbene coinage metal complexes', Tetrahedron, vol. 68, pp. 7949-7955.
Zhu, S, Liang, R, Chen, L, Wang, C, Ren, Y \& Jiang, H 2012, 'A direct and practical approach for the synthesis of $\mathrm{Au}(\mathrm{I})-\mathrm{NHC}$ complexes from commercially available imidazolium salts and Au(III) salts', Tetrahedron Letters, vol. 53, pp. 815-818.

Ziegler, T \& Rauk, A 1977, 'On the calculation of bonding energies by the Hartree Fock Slater method', Theor. Chim. Acta., vol. 46, pp. 1-10.

Ziegler, T \& Rauk, A 1979, 'A theoretical study of the ethylene-metal bond in complexes between copper(1+), silver(1+), gold(1+), platinum( $(0)$ or platinum $(2+)$ and ethylene, based on the HartreeFock-Slater transition-state method', Inorg. Chem., vol. 18, pp. 1558-1565. 